\title{
PROJETO DE EFICIÊNCIA DO FORNO STEIN COM AUTOMAÇÃO*
}

Wesley Alves Quintão ${ }^{1}$ Pedro Henrique Prudente ${ }^{2}$

\section{Resumo}

O projeto criado e aqui apresentado teve por objetivo atender as necessidades da empresa em relação às metas de economia de energia e adequação ao mercado atual e para isso foi estudada uma maneira de gerar economia de gás com o desligamento de pilotos de ignição e também eliminar atrasos mecânicos no processo de acendimento, purga e estanqueidade do forno de reaquecimento Stein, através do uso de recursos da automação, eliminando dispositivos eletromecânicos garantindo velocidade de informação, economia comprovada de gás e maior confiabilidade no sistema de monitoramento do processo.

Palavras-chave: Gás; Siderurgia; Automação; Forno

\section{STEIN FURNACE EFFICIENCY PROJECT THROUGH AUTOMATION Abstract}

This project has been created and presented to meet the company's needs concerning energy saving targets and adaptation to the current market. For this purpose, it was studied a way to generate gas saving through the shutdown of ignition pilots and also to eliminate mechanical delays in the firing process, purging and leak-tightness of the Stein reheating furnace through the use of automation resources, eliminating electromechanical devices and ensuring speed information, proven gas savings and higher system reliability in the process monitorinc.

Keywords: Gas; Steel Mill; Automation; Furnace.

1 Formando em Engenharia de Controle e Automação - UBM, Técnico em Manutenção Elétrica III, setor GLQ, Votorantim Siderurgia Barra Mansa, Rio De Janeiro, Brasil.

2 Técnico em Eletrônica SENAI-BM, Técnico em Manutenção Elétrica II, setor GLQ, Votorantim Siderurgia Barra Mansa, Rio de Janeiro, Brasil. 


\section{INTRODUÇÃO}

Hoje no país a situação econômica leva as empresas a elaborarem e aplicarem métodos que visam economia de energias, melhoria nos resultados e adequação á toda oscilação comercial e até política.

O consumo de gás natural nas indústrias siderúrgicas é crucial para gerar energia em fornos e hoje é um dos maiores impactos na receita de uma empresa que depende deste tipo de energia. São gastos milhões de reais por ano com consumo de gás natural.

Outra questão é a disponibilidade e agilidade de processos. Sabemos que desenvolver e produzir em tempo hábil faz toda diferença no resultado do produto, o que inclui qualidade e preço.

Possibilitar à operação um equipamento que atenda rapidamente a acionamentos com tempo fixo e disponibilidade garantida gera uma confiança no processo e a certeza de sucesso no mesmo.

Deste modo se faz necessário levantar e investir em recursos que incentivem práticas e idéias inovadoras para diminuir gastos com energia e até eliminá-los.

No forno de reaquecimento de tarugos Stein, instalado na Votorantim Siderurgia Barra Mansa, temos um alto consumo de gás natural que hoje é um desafio para os gestores.

Particularmente no processo de acendimento deste forno, existem quatro dispositivos chamados pilotos que têm a função de manter os queimadores da zonas de encharque acesos durante o aquecimento do forno porém durante a laminação permaneciam ligados ou seja, em regime permanente de trabalho.

Outro problema levantado era sobre o método de acendimento do forno onde o circuito predominante eram em grande parte formados por dispositivos eletromecânicos, o que resultava em atrasos de resposta, falhas e posteriormente dificuldade de análise e atrasos de operação.

Foi pensando nessas condições que foram desenvolvidos dois projetos para melhorar desempenho e se adequar ao quadro de economia, onde ideias e práticas com baixo ou até zero de custo ajudam manter a empresa competitiva no mercado.

Foram criados os projetos: Sistema Desligamento Automático dos Pilotos e Sistema de Acendimento do Forno.

\section{MATERIAIS E MÉTODOS}

\section{Sistema desligamento automático dos pilotos}

Para o sistema de economia de gás através do desligamento dos pilotos de acendimento nas zonas de encharque foi elaborada uma lógica em PLC em que o sistema identifica o momento em que o forno está em modo PRODUÇÃO e assim efetua o desligamento de cada piloto automaticamente. Da mesma forma, quando o forno está em modo AQUECIMENTO (processo parado) os pilotos são acionados automaticamente garantindo a ignição em baixas temperaturas.

O programa lógico de economia de gás foi elaborada em PLC, onde o recurso foi o tempo de elaboração do mesmo. O sistema foi aplicado em abril de 2015.

Para este trabalho, foi consultado o manual do fabricante do dispositivo piloto para se ter ideia de qual a vazão por hora este equipamento consumia para se manter aceso. Esta etapa foi necessária para conhecer melhor o funcionamento do 
equipamento e posteriormente criar uma base de cálculo para economia e no quesito manutenção, aumentar a vida útil do mesmo.

A figura abaixo mostra um trecho da lógica de desligamento.

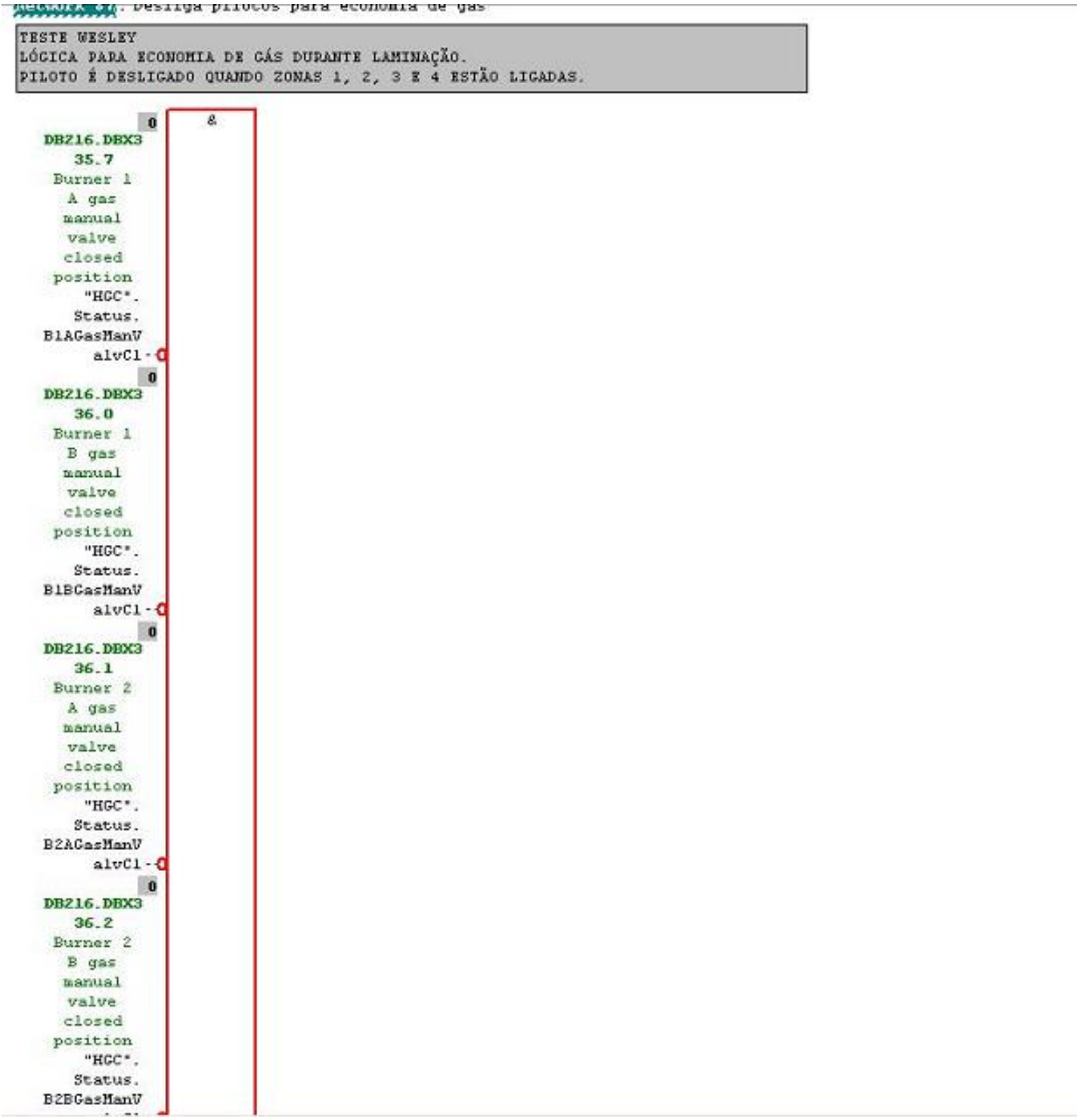

Figura 1. Trecho da lógica de desligamento

As fotos abaixo mostram o piloto e a unidade de controle que desligada durante o processo. 


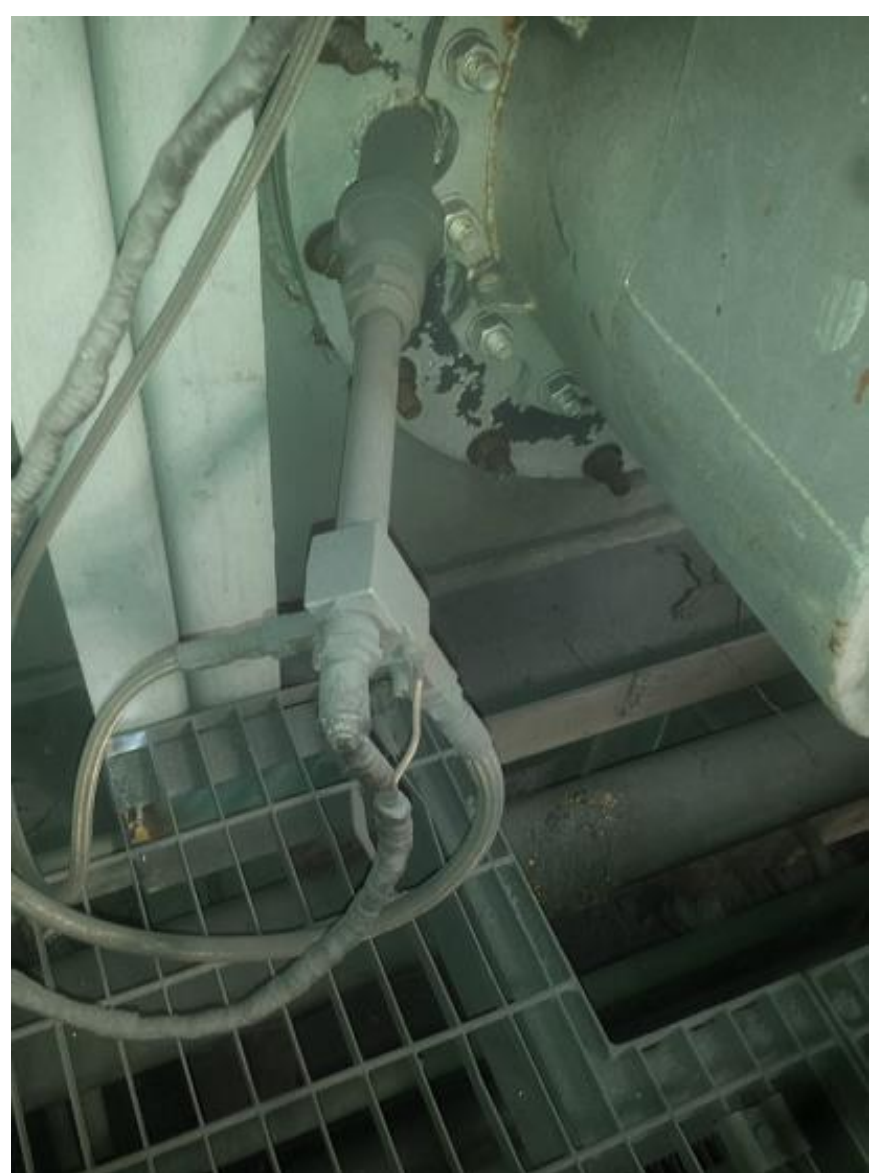

Foto 1. Piloto inserido no forno.

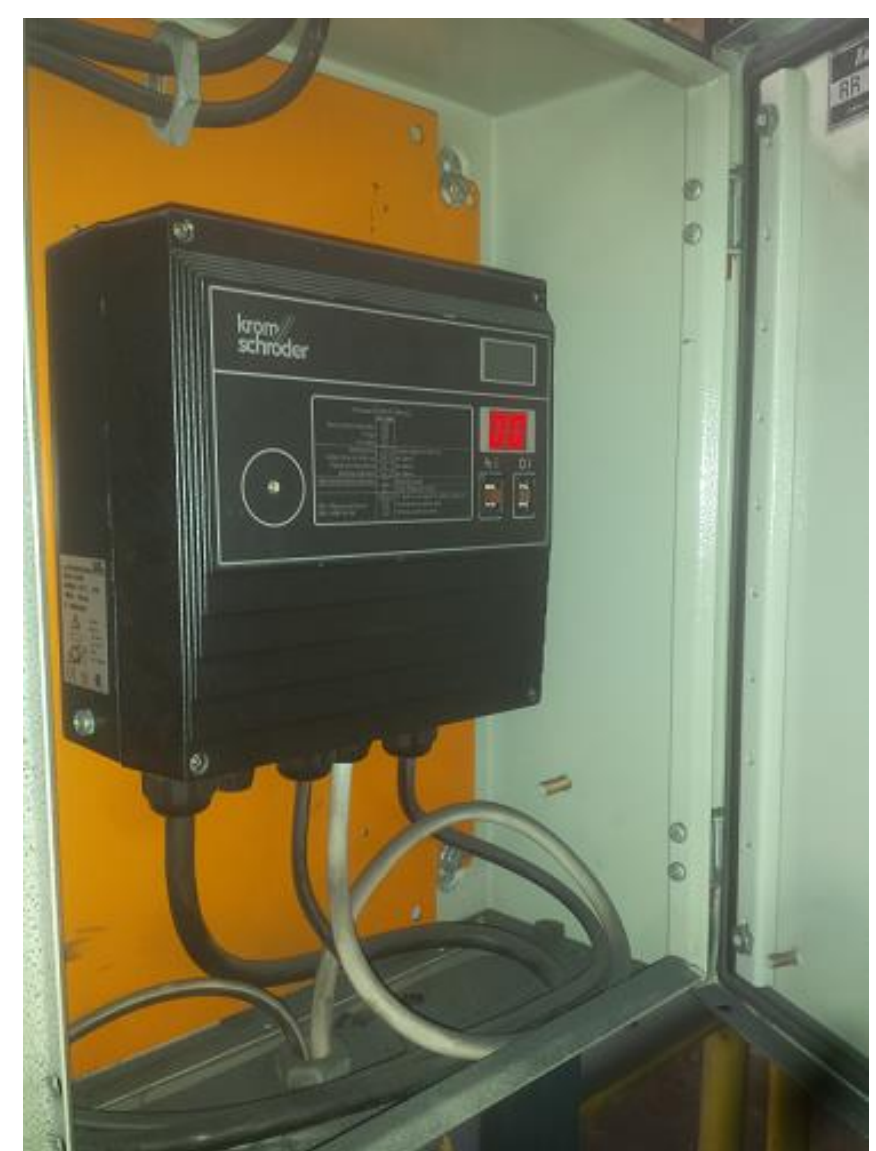

Foto 2. Unidade de controle do piloto que recebe o comando de desligamento. 
Para o sistema de acendimento do forno que engloba acendimento do forno e que antes era efetuado por uma série de trinta e seis dispositivos eletromecânicos entre contatores e relés temporizados, foi criada uma lógica que monitora e controla toda sequência padrão de acendimento de forno de reaquecimento.

Para elaborar o sistema de acendimento com purga e estanqueidade, inicialmente foram inseridas as quatro etapas da atividade no cronograma de uma parada programada de reparo do laminador, para retirada de todos os dispositivos e posteriormente inserção destes sinais diretamente no PLC, o que por sua vez considerou-se um tempo maior de criação e testes. Este trabalho foi executado e concluído em junho de 2015.

A primeira etapa deste trabalho foi mapear todos os dispositivos do painel no layout e entender todos os intertravamentos físicos entre eles.

Uma vez mapeados e interpretados, para seguimento da segunda etapa foram criadas variáveis para os sinais que deixariam de ser puramente físicos para se serem enviados ao PLC. Nesta fase foram criadas no bloco lógico referente ao acendimento do forno, que inclui purga e estanqueidade.

A terceira etapa foi a retirada de todos os dispositivos físicos do painel, incluindo cabos. Foram desativados trinta e seis dispositivos que foram encaminhados para se tornarem sobressalentes de outras áreas.

A quarta e última etapa foi o teste de acendimento que foi concluído com sucesso no dia de liberação do forno para aquecimento de tarugos para início de produção pós parada.

Para ambos os projetos não houveram gastos com equipamentos ou serviços e sim o aproveitamento de tempo e dedicação para elaboração e testes dos programas.

As ferramentas utilizadas na área de automação englobam PLC SIEMENS e programação em linguagem FBD.

A figura abaixo é uma parte da linguagem desta programação. 


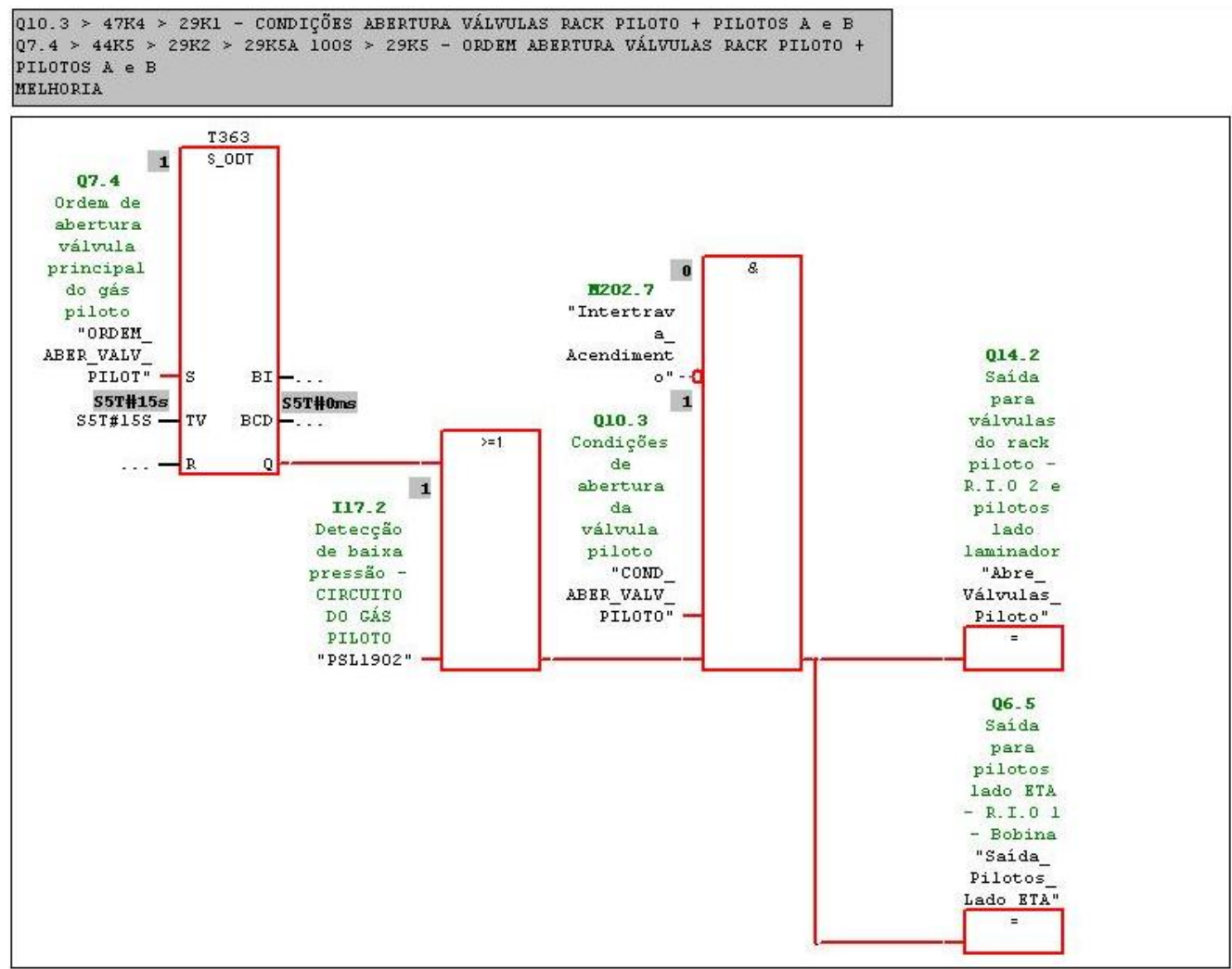

Figura 2. Trecho da lógica de programação para sequência de acendimento.

A foto abaixo mostra uma das remotas usadas para transição dos sinais para o PLC principal do Forno Stein.

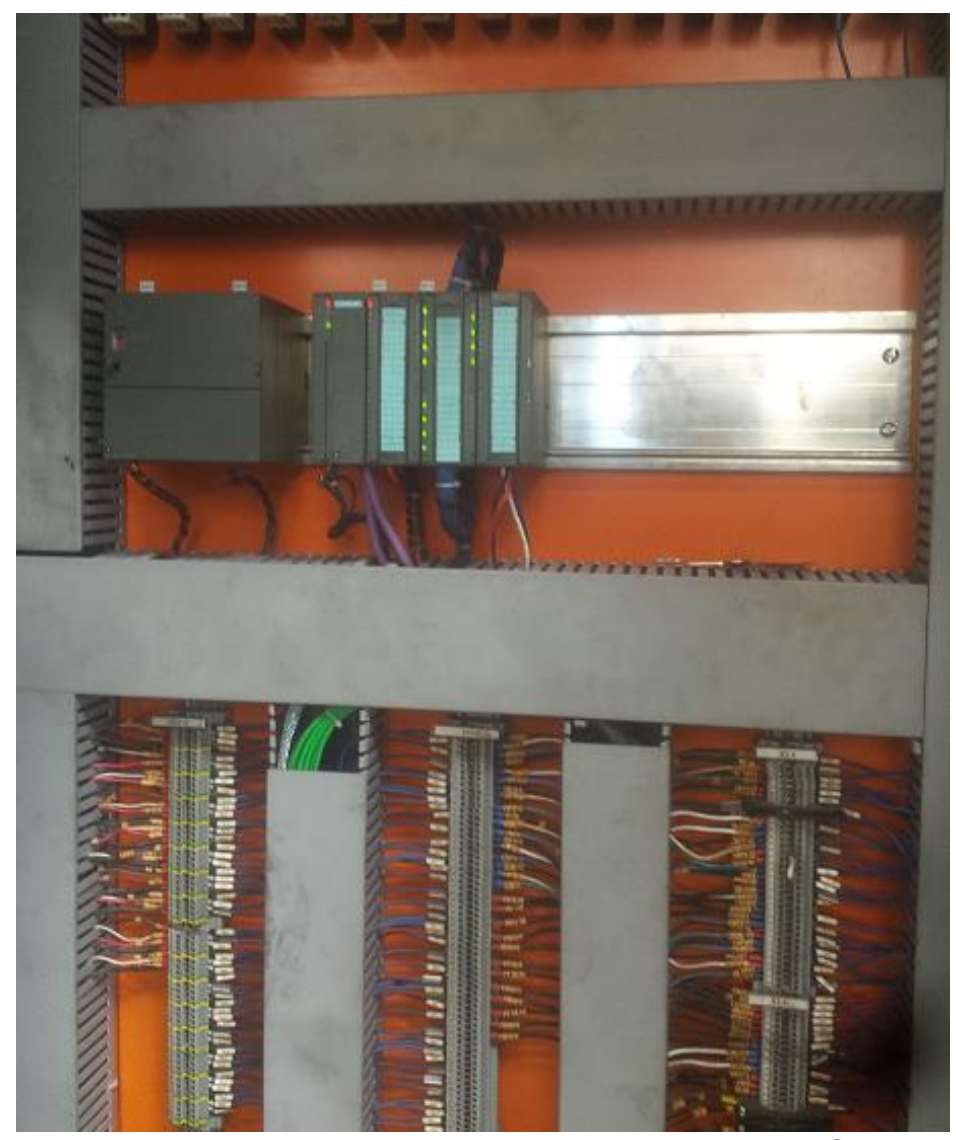

Foto 3. Remota e ligações de sinais para o PLC. 


\section{RESULTADOS E DISCUSSÃO}

\section{Desligamento Automático dos Pilotos}

O manual do fabricante informa que este modelo de piloto tem um consumo por hora de aproximadamente 8 metros cúbicos por hora de trabalho.

O regime de trabalho do piloto no processo era permanente e assim foi possível calcular qual seria essa economia mantendo-os acesos apenas em condição de produção para nos finais de semana.

Seguem resultados obtidos desde a aplicação do projeto de desligamento automático do piloto (Tabela 1).

\begin{tabular}{|l|c|c|c|c|}
\hline & HORA & DIA & MÊS ** & ANO*** \\
\hline $\begin{array}{l}\text { VAZÃO } \\
\text { (Em metros } \\
\text { cúbicos por } \\
\text { hora) }\end{array}$ & $8 \mathrm{m3} / \mathrm{h}$ & $192 \mathrm{m3} / \mathrm{h}$ & $4.992 \mathrm{m3} / \mathrm{h}$ & $59.904 \mathrm{m3} / \mathrm{h}$ \\
\hline $\begin{array}{l}\text { ECONOMIA } \\
\text { (Em moeda R\$) }\end{array}$ & $\mathrm{R} \$ 1,05$ & $\mathrm{R} \$ 201,60$ & $\mathrm{R} \$ 5.241,60$ & $\mathrm{R} \$ 62.900,00 *$ \\
\hline
\end{tabular}

Tabela 1. Economia de gás pelo desligamento do piloto.

* O valor é o obtido em um ano desde o start-up da lógica.

** Considerando 26 dias do mês em que o forno é utilizado para processo.

*** Considerando apenas os dias em que o forno é utilizado para processo no ano (aprox 312 dias).

Além da economia em dinheiro, temos a extensão da vida útil do dispositivo que saiu de uma condição de regime permanente e passou a atuar apenas na condição de produção parada em finais de semana. A degradação ao material é menor e sua disponibilidade aumenta.

\section{Sistema de Acendimento do Forno}

Segue uma lista de problemas comuns antes da transição dos sinais:

1 - Queima de relés que geravam permissíveis;

2 - Agarramento de contatos em série que posteriormente bloqueavam a sequência de acendimento;

3 - Tempo alto de análise para verificar em qual etapa física do processo de acendimento o problema se encontrava;

4 - Contato danificado provocando falhas intermitentes;

5 - Tempo de parada impactava na produção.

Desde a transição do processo de acendimento do forno para uma condição totalmente lógica, não houveram mais problemas referentes à acendimento de forno. O processo que antes dependia de temporizadores físicos e ainda sofria com atrasos mecânicos hoje está com uma sequência de tempo fixa pelo PLC e assim o forno é aceso de forma uniforme e rápida.

Para a operação tornou-se um procedimento mais confiável e totalmente monitorado. 
Para a manutenção o ganho foi muito maior conforme lista abaixo:

1 - Monitoramento e controle completo pelo PLC;

2 - Eliminação de pontos críticos suscetíveis à falha externa;

3 - Padronização de sistema em PLC, integrando todo processo ao mesmo;

4 - Aprendizado em programação e teste;

5 - Criar e encarar desafios que possibilitem ganhos e aprendizados;

6 - Administrar projetos dentro de prazos e entregá-los com sucesso e confiabilidade;

7 - Economia em material sobressalente.

A tabela abaixo mostra o valor aproximado na economia em sobressalentes.

Tabela 2. Economia em sobressalente.

\begin{tabular}{|l|c|c|c|}
\hline DISPOSITIVOS & QUANTIDADE & $\begin{array}{c}\text { VALOR EM } \\
\text { MÉDIA UNITÁRIO }\end{array}$ & $\begin{array}{c}\text { VALOR } \\
\text { TOTAL }\end{array}$ \\
\hline CONTATORES & 26 & $\mathrm{R} \$ 600,00$ & $\mathrm{R} \$ 15.600,00$ \\
\hline $\begin{array}{l}\text { RELÉS } \\
\text { TEMPORIZADOS }\end{array}$ & 8 & $\mathrm{R} \$ 400,00$ & $\mathrm{R} \$ 3.200,00$ \\
\hline $\begin{array}{l}\text { CONTATOR GERAL DE } \\
\text { SINAIS }\end{array}$ & 2 & $\mathrm{R} \$ 1.200,00$ & $\mathrm{R} \$ 2.400,00$ \\
\hline TOTAL & 36 & $\mathrm{R} \$ 2.200,00$ & $\mathrm{R} \$ 21.200,00$ \\
\hline
\end{tabular}

\section{CONCLUSÃO}

Adequar-se a situação industrial e comercial do país é necessidade de sobrevivência e aprimorar conhecimento e ideias direcionando tudo às ações nas áreas, mostram os quanto preparados e atentos estão as equipes sobre o atual quadro. Este é o rumo que as gestões devem incentivar e investir: criatividade.

Todos os objetivos traçados para este projeto foram atingidos conforme o desejado, o que deixa claro que com boas ideias, planejamento e ferramentas adequadas, é possível criarmos métodos de ganhos para a empresa, mantendo o ideal de competitividade, metas e estímulo aos empregados para pensarem além do que estão acostumados a fazer.

Sobre os ganhos diretos do projeto, sem dúvidas devemos ressaltar o papel importante da automação em seu start-up. Uma vez que o uso do PLC é determinante no controle e sua disponibilidade na planta já é real, cabe-nos aproveitar as ferramentas existentes, criar novos programas e e gerar recursos que facilitem e agilizem processos, possibilitem segurança e criam um clima de conforto para os profissionais diretamente envolvidos.

Uma vez que economia em energia é um dos grandes desafios para as empresas, toda oportunidade deve ser aproveitada e explorada ao máximo.

Criar, acreditar e aplicar são ganhos imensuráveis para a empresa e seus colaboradores.

\section{Agradecimentos}

Aos gestores pelo apoio à divulgação destes trabalhos.

\section{REFERÊNCIAS}

Manual KROM SCHRODER; 2008. 